\title{
DESEMPENHO AGRONÔMICO DO MILHO EM RAZÃO DO TRATAMENTO DE SEMENTES COM Azospirillum sp. E DA APLICAÇÃO DE DOSES DE NITROGÊNIO MINERAL
}

\author{
Luís Sangoi(1), Ligia Maria Maraschi da Silva ${ }^{(2)}$, Murilo Renan Mota ${ }^{(3)^{*}}$, Fernando Panison ${ }^{(4)}$, \\ Amauri Schmitt ${ }^{(4)}$, Natalia Maria de Souza ${ }^{(4)}$, Willian Giordani ${ }^{(5)}$ e Diego Eduardo \\ Schenatto $^{(5)}$ \\ (1) Universidade do Estado de Santa Catarina, Departamento de Agronomia, Lages, Santa Catarina, Brasil. \\ (2) Universidade Federal da Grande Dourados, Programa de Pós-graduação em Produção Vegetal, Dourados, Mato Grosso do Sul, Brasil. \\ (3) Universidade do Estado de Santa Catarina, Departamento de Solos, Programa de Pós-Graduação em Ciência do Solo, Lages, \\ Santa Catarina, Brasil. \\ (4) Universidade do Estado de Santa Catarina, Departamento de Agronomia, Programa de Pós-Graduação em Produção Vegetal, \\ Lages, Santa Catarina, Brasil. \\ (5) Universidade deoEstado de Santa Catarina, Curso de Agronomia, Lages, Santa Catarina, Brasil. \\ * Autor correspondente. \\ E-mail: mure_mota@hotmail.com
}

\section{RESUMO}

A utilização de bactérias diazotróficas pode auxiliar a alcançar maiores produtividades e reduzir os impactos ambientais decorrentes da utilização de fertilizantes nitrogenados. Este trabalho foi conduzido com o objetivo de avaliar o efeito do tratamento de sementes com bactérias do gênero Azospirillum e da aplicação de doses de N mineral sobre o desempenho agronômico do milho em diferentes níveis de manejo. $O$ experimento foi conduzido no campo, na cidade de Lages, SC, durante os anos agrícolas de 2011/2012 e 2012/2013. Utilizou-se o delineamento experimental de blocos ao acaso dispostos em parcelas subsubdivididas. Na parcela principal, foram testados dois níveis de manejo, o médio, expectativa de produtividade de $8.000 \mathrm{~kg} \mathrm{ha}^{-1}$; e o alto, expectativa de produtividade de $18.000 \mathrm{~kg} \mathrm{ha}^{-1}$. Nas subparcelas, testaram-se quatro doses de $\mathrm{N}$, equivalentes a $0 ; 0,5 ; 1 ;$ e 1,5 vez a dose recomendada pela Comissão Sul Brasileira de Química e Fertilidade do Solo para atingir a expectativa de produtividade prevista em cada nível de manejo. Nas subsubparcelas, avaliou-se o efeito do tratamento de sementes com Azospirillum sp. O rendimento de grãos variou de 8.344 a $16.947 \mathrm{~kg} \mathrm{ha}^{-1}$ no nível de manejo alto e aumentou quadraticamente com o aumento das doses 
de $\mathrm{N}$, tanto nas parcelas inoculadas quanto nas não inoculadas. No nível de manejo médio, os rendimentos oscilaram entre 5.986 e $9.684 \mathrm{~kg} \mathrm{ha}^{-1}$, aumentaram linearmente com o incremento na dose de $\mathrm{N}$ nos tratamentos inoculados e não foram influenciados pela aplicação de $\mathrm{N}$ mineral nos tratamentos sem inoculação. Nos dois sistemas de manejo, a eficiência de uso do $\mathrm{N}$ diminuiu com o incremento na dose de $\mathrm{N}$, tanto nas parcelas inoculadas quanto nas não inoculadas. Não houve diferenças significativas no rendimento de grãos dos tratamentos com e sem inoculação, independentemente do sistema de manejo e da dose de N. Portanto, o tratamento de sementes com Azospirillum sp. não melhorou o desempenho agronômico do milho.

Palavras-chave: Zea mays, inoculação, bactérias diazotróficas, cobertura nitrogenada.

\title{
ABSTRACT: MAIZE AGRONOMIC PERFORMANCE AS AFFECTED BY SEED TREATMENT WITH Azospirillum sp. AND MINERAL NITROGEN RATES
}

\begin{abstract}
The use of diazotrophic bacteria can help to achieve higher yields and reduce negative environmental impacts caused by $N$ fertilizers. The aim of this study was to evaluate the effects of seed treatment with Azospirillum bacteria and the application of different rates of mineral $N$ on maize agronomic performance at two levels of yield management. A field experiment was set up in Lages, SC, Brazil, in the 2011/2012 and 2012/2013 growing seasons. A randomized block experimental design arranged in split-split plots was used. Two yield management levels were tested in the main plots: medium (grain yield expectation of 8,000 $\mathrm{kg} \mathrm{ha}^{-1}$ ) and high (grain yield expectation of 18,000 $\mathrm{kg} \mathrm{ha}^{-1}$ ). Four $\mathrm{N}$ rates were assessed in the split plots, rates equivalent to 0, 0.5, 1.0, and 1.5 times the rate recommended by the Southern Brazil Commission of Soil Chemistry and Fertility to achieve the yield expectation at each level of yield management. The effect of seed treatment with Azospirillum sp. was evaluated in the split-split plots. Grain yield ranged from 8,344 to 16,947 $\mathrm{kg} \mathrm{ha}^{-1}$ at the high management level and increased quadratically with the increase in $N$ rate, both with and without Azospirillum seed treatment. At the medium management level, grain yield ranged from 5,986 to 9,684 $\mathrm{kg} \mathrm{ha}^{-1}$. It increased linearly with the increase in $N$ rate when seeds were treated with Azospirillum and was not affected by mineral N in treatments without seed inoculation. The efficiency of $N$ use decreased when $N$ rates increased at both yield management levels and whether the seeds were inoculated or not. There was no significant difference in grain yield between inoculated and non-inoculated treatments, regardless of the yield management level or $N$ rate. Therefore, seed treatment with Azospirillum sp. did not improve the agronomic performance of maize.
\end{abstract}

Keywords: Zea mays, inoculation, diazotrophic bacteria, sidedress nitrogen.

\section{INTRODUÇÃO}

Apesar da relevância da cultura do milho na economia do Brasil, a produtividade média do país tem se situado em torno de $5.000 \mathrm{~kg} \mathrm{ha}^{-1}$ nas últimas safras (Conab, 2013). Esse valor é muito baixo, se comparado aos rendimentos superiores a $10.000 \mathrm{~kg} \mathrm{ha}^{-1}$, que têm sido obtidos em condições experimentais ou da produtividade média de países como os Estados Unidos (Sangoi et al., 2010a).

A grande lacuna existente entre o rendimento médio da lavoura brasileira e o que é verificado sob condições de alto manejo pode ser atribuída a várias causas, como o uso de genótipos com baixo potencial produtivo ou não adaptado à região de cultivo, as épocas de semeadura impróprias, a escolha inadequada do arranjo de plantas e a aplicação de baixas doses de fertilizantes nitrogenados (Sangoi et al., 2010b).

$\mathrm{O} \mathrm{N}$ é o nutriente mineral que exerce maior influência na produtividade de grãos e também o que mais onera o custo de produção (Silva et al., 2005). Ele é fundamental para o estabelecimento e a duração da área foliar, bem como para a formação das espigas, interferindo tanto na magnitude da fonte produtora de fotoassimilados quanto na força do dreno que irá recebê-los (Rambo et al., 2007).

$\mathrm{O}$ milho remove grandes quantidades de $\mathrm{N}$. Quando se desejam produtividades elevadas, recomenda-se adubação nitrogenada em cobertura para complementar a quantidade suprida pelo solo. A quantidade de $\mathrm{N}$ que deve ser aplicada em cobertura é variável. Em sistemas de elevado nível tecnológico, onde se faz uso de irrigação, a recomendação de $\mathrm{N}$ pode chegar a $250 \mathrm{~kg}$ ha-1 para obter elevadas produtividades (Coelho, 2000). Nessas situações, o fertilizante nitrogenado pode representar de 15 a $20 \%$ dos custos variáveis da lavoura (Debruin e Butzen, 2014).

Além da necessidade de reduzir custos com adubação nitrogenada, também é crescente a preocupação com a poluição dos recursos hídricos 
e da atmosfera causados pelo uso inadequado de fertilizantes nitrogenados, em virtude da instabilidade desse nutriente, o que pode deixá-lo sujeito a perdas por erosão, lixiviação, volatilização e desnitrificação (Lara Cabezas et al., 2000).

Dessa forma, a identificação de estratégias de manejo da lavoura que possam atender a demanda nitrogenada do milho, com baixo custo de produção e limitado impacto ambiental, torna-se cada vez mais importante para aumentar a margem bruta do produtor, preservar o ambiente e garantir segurança alimentar para a população mundial.

Entre as alternativas na busca de sistemas sustentáveis de produção de milho, visando redução na aplicação e no aumento na eficiência na utilização do N, destaca-se o uso de bactérias capazes de promoverem a fixação biológica de $\mathrm{N}$ (FBN). Esses microrganismos, chamados diazotróficos, são capazes de reduzir o $\mathrm{N}$ atmosférico $\left(\mathrm{N}_{2}\right)$ a amônia $\left(\mathrm{NH}_{3}^{+}\right)$pela quebra da ligação tríplice do $\mathrm{N}$ pela enzima nitrogenase, com alto consumo de energia na forma de ATP. Após a reação de redução, a amônia é rapidamente convertida a amônio $\left(\mathrm{NH}_{4}^{+}\right)$, que é assimilado pela célula vegetal sob a forma de glutamina. A FBN é complexa e depende da expressão de um conjunto de genes que codificam as proteínas envolvidas no processo (Reis e Teixeira, 2005).

$\mathrm{Na}$ família Poaceae, a FBN é conhecida desde que a bactéria Beijerinckia fluminensis foi isolada da rizosfera de cana-de-açúcar. Contudo, foi somente após a redescoberta de bactérias do gênero Azospirillum que aumentou o interesse pelo estudo da FBN em gramíneas (Baldani e Baldani, 2005). Várias bactérias diazotróficas foram isoladas da cultura de milho, destacando-se as espécies Azospirillum lipoferum, A. brasilense e Herbaspirillum seropedicae (Reis et al., 2000).

Em razão do alto custo energético da FBN, alguns fatores regulam a atividade da nitrogenase, destacando-se a concentração de $\mathrm{O}_{2}$, disponibilidade energética da célula, idade fisiológica (Rodrigues et al., 2006) e disponibilidade de N, principalmente na forma de $\mathrm{NH}_{4}^{+}$(Prakamhang et al., 2009).

As bactérias diazotróficas também podem atuar estimulando o crescimento vegetal, gerando aumento na atividade da redutase do nitrato quando crescem endofiticamente nas plantas (Cassán et al., 2008). Essas também auxiliam na produção de hormônios como auxinas, citocininas, giberelinas, etileno e atuam como agentes de controle biológico de patógenos (Correa et al., 2008). Em geral, acredita-se que as bactérias promotoras de crescimento beneficiam o crescimento das plantas pela combinação de todos esses mecanismos (Dobbelaere et al., 2003).

A atuação das bactérias diazotróficas é influenciada pela dose de $\mathrm{N}$ aplicada, que depende do nível de manejo adotado pelo produtor e da sua capacidade de investimento na lavoura. Assim, é importante entender essa interação para a adoção de uma estratégia correta na escolha do inoculante, bem como na adoção de uma dose de $\mathrm{N}$ que otimize o desempenho das bactérias e da cultura, para diferentes situações de investimentos em manejo.

Uma das principais limitações à utilização do Azospirillum na cultura do milho é a inconsistência dos resultados de pesquisa, que variam de acordo com a cultivar, as condições edafoclimáticas e a metodologia de condução dos ensaios (Bartchechen et al., 2010). Este trabalho objetivou avaliar o desempenho agronômico do milho em razão do tratamento de sementes com bactérias do gênero Azospirillum e de diferentes doses de $\mathrm{N}$ mineral, em dois níveis de manejo.

\section{MATERIAL E MÉTODOS}

O experimento foi conduzido na cidade de Lages, Santa Catarina, durante os anos agrícolas de 2011/12 e 2012/2013. As coordenadas geográficas do local são $27^{\circ} 50^{\prime} 35^{\prime}$ 'de latitude sul e $50^{\circ} 02$ ' $45^{\prime \prime}$ de longitude oeste, com altitude de $849 \mathrm{~m}$. O clima da região é do tipo Cfb mesotérmico, com verões brandos, temperaturas médias do mês mais quente inferiores a $22{ }^{\circ} \mathrm{C}$ e precipitações pluviais bem distribuídas, de acordo com a classificação de Köppen.

O solo da área experimental é classificado como Nitossolo Vermelho distrófico típico (Embrapa, 2006). A análise do solo, realizada em setembro de 2011, evidenciou que ele apresentava $420 \mathrm{~g} \mathrm{~kg}^{-1}$ de argila; $50,0 \mathrm{~g} \mathrm{~kg}^{-1}$ de matéria orgânica; $\mathrm{pH}\left(\mathrm{H}_{2} \mathrm{O}\right) 5,6$; índice SMP de 5,8; $5 \mathrm{mg} \mathrm{dm}^{-3}$ de $\mathrm{P} ; 0,50 \mathrm{cmol}_{\mathrm{c}} \mathrm{kg}^{-1} \mathrm{de} \mathrm{K}^{+}$;

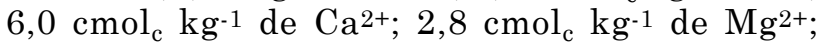
0,3 $\mathrm{cmol}_{\mathrm{c}} \mathrm{kg}^{-1} \mathrm{de} \mathrm{Al}^{3+} ;$ e CTC de 15,3 $\mathrm{cmol}_{\mathrm{c}} \mathrm{kg}^{-1}$.

A área experimental é cultivada em sistema de semeadura direta desde 1999, utilizando a rotação de culturas com soja (Glycine max L.) e milho (Zea mays L.) e sucessão com o consórcio de aveia-preta (Avena strigosa) e ervilhaca (Vicia sativa).

$\mathrm{O}$ delineamento experimental utilizado foi de blocos casualizados dispostos em parcelas subsubdivididas, com quatro repetições por tratamento. Na parcela principal, foram alocados os níveis manejo médio e alto, em que as expectativas de produtividade almejadas foram de 8.000 e $18.000 \mathrm{~kg} \mathrm{ha}^{-1}$, respectivamente. Nas subparcelas, foram alocadas as doses de $\mathrm{N}$, correspondendo a 0 ; 0,$5 ; 1 ; \mathrm{e} 1,5$ vez a dose recomendada pela CQFSRS/SC (2004) para cada expectativa de produtividade, o que resultou em 30, 65, 130 e $195 \mathrm{~kg} \mathrm{ha}^{-1}$ de $\mathrm{N}$, para o nível de manejo médio; e 30, 140, 280 e $420 \mathrm{~kg} \mathrm{ha}^{-1}$ de $\mathrm{N}$, para o nível de manejo alto. Nos dois níveis de manejo, foram aplicados $30 \mathrm{~kg} \mathrm{ha}^{-1}$ de $\mathrm{N}$ na 
semeadura; e o restante da dose prevista, em cada tratamento em cobertura. Nas subsubparcelas foram testadas a presença ou ausência da inoculação das sementes com Azospirillum brasiliense. Cada subsubparcela foi composta por quatro linhas de $6 \mathrm{~m}$ de comprimento. Todas as avaliações foram feitas nas duas fileiras centrais.

No nível de manejo médio, utilizou-se a variedade de polinização aberta (VPA) SCS 155 Catarina e a densidade de 50.000 plantas ha-1. Realizou-se a adubação de manutenção no dia da semeadura conforme expectativa de produtividade, aplicando-se $30 \mathrm{kgha}^{-1} \mathrm{deN}, 145 \mathrm{kgha}^{-1} \mathrm{de}_{2} \mathrm{O}_{5}$ e $70 \mathrm{~kg} \mathrm{ha}^{-1} \mathrm{de} \mathrm{K}_{2} \mathrm{O}$. A adubação de $\mathrm{N}$ em cobertura foi realizada numa única aplicação, feita quando as plantas encontravam-se no estádio fenológico V8 (oito folhas expandidas) da escala de Ritchie et al. (1993).

No nível de manejo alto, buscou-se dar condições para que a cultura do milho pudesse expressar seu máximo potencial produtivo. Para isso, utilizou-se o híbrido simples (HS) P30R50H e a densidade de 90.000 plantas ha-1. Realizou-se adubação almejando produtividade de $18.000 \mathrm{~kg} \mathrm{ha}^{-1}$, aplicando-se no dia da semeadura $30 \mathrm{~kg} \mathrm{ha}^{-1}$ de $\mathrm{N}, 295 \mathrm{~kg} \mathrm{ha}^{-1}$ de $\mathrm{P}_{2} \mathrm{O}_{5}$ e $170 \mathrm{~kg}$ ha-1 de $\mathrm{K}_{2} \mathrm{O}$. Foi efetuado um tratamento fitossanitário com os fungicidas azoxistrobina + ciproconazol no estádio fenológico de V12 (12 folhas expandidas) da escala de Ritchie et al. (1993). A adubação de cobertura com $\mathrm{N}$ foi feita conforme as doses de cada tratamento, na linha de semeadura, sendo fracionada igualmente em três partes iguais, nos estádios fenológicos de V4, V8 e V12 da escala de Ritchie et al. (1993). A fonte de $\mathrm{N}$ utilizada no ensaio foi ureia.

As semeaduras das unidades experimentais foram realizadas nos dias 19 de outubro de 2011 e 21 de outubro de 2012, utilizando semeadoras manuais. Foram depositadas três sementes por cova para que se obtivesse a garantia do estande. Posteriormente, quando as plantas se encontravam no estádio fenológico de V3 (três folhas expandidas) da escala de Ritchie et al. (1993), foi feito o desbaste, buscando-se estabelecer o número de plantas correspondentes às densidades de cada tratamento. O espaçamento entrelinhas para ambos os níveis de manejo foi de $0,7 \mathrm{~m}$.

As sementes foram tratadas no dia da semeadura com inseticida à base de imidacloprid + tiodicarbe (3 mL kg-1 de sementes) e com fungicida à base de fludioxonil + metalaxyl-m $\left(1,5 \mathrm{~mL} \mathrm{~kg}^{-1} \mathrm{de}\right.$ sementes) para controle preventivo de pragas e doenças na fase inicial do ciclo da cultura. Após o tratamento de sementes com inseticida e fungicida e imediatamente antes da operação da semeadura, as sementes dos tratamentos com inoculação foram misturadas com bactérias do gênero Azospirillum, utilizando o produto comercial Masterfix Gramíneas, na dose de $5 \mathrm{~mL} \mathrm{~kg}^{-1} \mathrm{de}$ sementes, equivalente à dose recomendada pelo fabricante de $100 \mathrm{~mL}$ do inoculante comercial por ha-1. A inoculação foi feita minutos antes da semeadura. Para tanto, foram utilizados sacos plásticos onde as sementes receberam o produto. Para homogeneizar a distribuição da solução, as sementes foram agitadas por aproximadamente 5 min após a aplicação do produto.

Para o controle de plantas daninhas, foram efetuadas duas aplicações de herbicida. A primeira foi feita em pré-emergência, logo após a semeadura, com uma mistura de atrazina e s-metolaclor $\left(1,25+1,25 \mathrm{~kg} \mathrm{ha}^{-1}\right)$. A segunda aplicação foi realizada em pós-emergência quando as plantas de milho estavam no estádio V4, utilizando-se o produto tembotriona (100 g ha-1). Para o controle de pragas, foram realizadas duas aplicações dos inseticidas lufenuron+lambdacyhalothrin $\left(15+7,5 \mathrm{~g} \mathrm{ha}^{-1}\right)$, quando as plantas estavam nos estádios V6 e V12 da escala de Richie et al. (1993).

Quando as plantas alcançaram o estádio R1 (espigamento) da escala de Richie et al. (1993), efetuou-se a avaliação do número de folhas senescidas e do índice do teor relativo de clorofila (TRC). O número de folhas senescidas foi determinado pela contagem do número de folhas que apresentavam menos de $50 \%$ da área foliar verde. Para determinar o TRC, utilizou-se a folha índice localizada no mesmo nó do colmo onde estava inserida a espiga superior da planta. A estimativa do TRC foi feita com o clorofilômetro SPAD 502 Plus.

A colheita das espigas foi feita manualmente nos dias 20 de abril de 2012 e 25 de abril de 2013 , quando a umidade dos grãos estava entre $18 \mathrm{e}$ $25 \%$. As espigas foram trilhadas e secas em estufa sob temperatura de aproximadamente $65^{\circ} \mathrm{C}$, até atingirem massa constante. Posteriormente, foram pesadas para determinar o rendimento de grãos (expresso na umidade de $130 \mathrm{~g} \mathrm{~kg}^{-1}$ ) e dos componentes de rendimento (massa de 1.000 grãos, número de grãos por espiga e número de espigas por $\mathrm{m}^{2}$ ).

A eficiência agronômica de uso do $\mathrm{N}$ foi determinada segundo Fageria e Baligar (2005), em que $\mathrm{EA}=(\mathrm{PGcf}-\mathrm{PGsf}) /(\mathrm{QNa})$, expressa $\mathrm{em} \mathrm{kg} \mathrm{kg-1}$, em que EA é a eficiência agronômica; PGcf, a produção de grãos com fertilizante nitrogenado; PGsf, a produção de grãos sem fertilizante nitrogenado; e $\mathrm{QNa}$, a quantidade em $\mathrm{kg}$ de $\mathrm{N}$ aplicado.

Nos dois anos de condução do experimento, se efetuou irrigação complementar sempre que o teor de umidade no solo medido por tensiomêtros foi inferior a -0,4 $\mathrm{MPa}$. O monitoramento da precipitação foi realizado a partir da instalação de pluviômetros na área experimental. Na figura 1, são apresentados os dados de precipitação registrados no local de condução do trabalho durante os estádios de desenvolvimento da cultura. 




Estádio de desenvolvimento e mês do ano

Figura 1. Precipitação pluvial e estádios fenológicos do milho nos anos agrícolas 2011/2012 e 2012/2013, em Lages, SC.

Os dados obtidos em cada ano agrícola foram avaliados estatisticamente pela análise de variância, utilizando o teste $\mathrm{F}$ em nível de significância de $5 \%$. Quando os valores de $\mathrm{F}$ foram significativos, as médias dos fatores qualitativos (nível de manejo e inoculação) foram comparadas entre si pelo teste de Tukey. Para avaliar o efeito das doses crescentes de No, procedeu-se uma análise de regressão polinomial, testando-se os modelos linear e quadrático. Tanto o teste de médias quanto a análise de regressão foram avaliados em nível de significância de $5 \%$.

\section{RESULTADOS E DISCUSSÃO}

Nos dois anos agrícolas em que se conduziu o experimento, o efeito dos tratamentos (níveis de manejo, doses de $\mathrm{N}$ e inoculação com Azospirillum) sobre as variáveis analisadas foi similar. Consequentemente, os resultados apresentados nos quadros e nas figuras do trabalho representam a média dos anos agrícolas de 2011/2012 e 2012/2013.

O número de folhas senescidas no início do enchimento de grãos foi influenciado pela interação entre dose $\times$ inoculação e pelo sistema de manejo da cultura. Nos dois níveis de manejo, esse decresceu linearmente com o aumento na dose de $\mathrm{N}$ nas parcelas inoculadas e não foi influenciado significativamente pela quantidade de fertilizante mineral aplicada em cobertura nas parcelas não inoculadas (Figura 2). Pelo comportamento, concluiu-se que houve interação entre as contribuições do $\mathrm{N}$ mineral e do fornecido pela bactéria, que ocasionou o retardamento da senescência foliar das plantas inoculadas. As bactérias diazotróficas podem contribuir não
Quadro 1. Número de folhas senescidas e teor relativo de clorofila na folha índice do milho em razão do nível de manejo (alto e médio), da dose de nitrogênio em razão do nível tecnológico e da inoculação ou não das sementes com Azospirillum, em Lages, SC

\begin{tabular}{|c|c|c|c|}
\hline Dose de N & Azospirillum & $\begin{array}{c}\text { Folha } \\
\text { senescida }\end{array}$ & $\begin{array}{c}\text { Teor relativo } \\
\text { de clorofila }\end{array}$ \\
\hline \multirow[t]{2}{*}{$\mathrm{kg} \mathrm{ha}^{-1}$} & & $\mathrm{n}^{\mathrm{o}}$ & Índice SPAD \\
\hline & & Nível alto & \\
\hline \multirow[t]{2}{*}{0} & Sem & 11,7 & 29,9 \\
\hline & Com & 11,0 & 32,2 \\
\hline \multirow[t]{2}{*}{140} & Sem & 10,4 & 43,5 \\
\hline & Com & 9,6 & 43,5 \\
\hline \multirow[t]{2}{*}{280} & Sem & 7,8 & 52,5 \\
\hline & Com & 8,3 & 50,5 \\
\hline \multirow[t]{2}{*}{420} & Sem & 8,0 & 51,0 \\
\hline & Com & 8,0 & 52,5 \\
\hline \multirow[t]{2}{*}{ Média } & & $9,4 \mathrm{~b}^{*}$ & $44,4 \mathrm{~b}$ \\
\hline & & Nível médio & \\
\hline \multirow[t]{2}{*}{0} & Sem & 12,2 & 33,2 \\
\hline & Com & 12,1 & 33,2 \\
\hline \multirow[t]{2}{*}{65} & Sem & 11,8 & 43,6 \\
\hline & Com & 11,1 & 49,0 \\
\hline \multirow[t]{2}{*}{130} & Sem & 9,1 & 53,1 \\
\hline & Com & 10,5 & 56,6 \\
\hline \multirow[t]{2}{*}{195} & Sem & 9,0 & 57,0 \\
\hline & Com & 9,3 & 54,9 \\
\hline Média & & $10,6 \mathrm{a}$ & $47,6 \mathrm{a}$ \\
\hline \multirow[t]{2}{*}{ Média da inoculação } & Sem & 9,9 a & $45,5 \mathrm{a}$ \\
\hline & Com & $10,1 \mathrm{a}$ & $46,5 \mathrm{a}$ \\
\hline CV (\%) & & 6,89 & 4,93 \\
\hline
\end{tabular}

Médias seguidas pela mesma letra minúscula na coluna não diferem estatisticamente pelo Teste Tukey $(\mathrm{p}<0,05)$.

apenas com aporte suplementar de $\mathrm{N}$, mas também com a produção de hormônios que estimulam o crescimento e desenvolvimento das plantas, bem como retardamento de senescência foliar (Lambrecht et al., 2000; Quadros, 2009). Isso pode interferir no número de folhas senescidas no espigamento das plantas inoculadas e não inoculadas.

Houve maior número de folhas senescidas no sistema de médio manejo do que no de alto (Quadro 1). Entretanto, o índice relativo de clorofila medido pelo clorofilômetro foi mais alto no sistema de médio do que no de alto manejo. Provavelmente, esse comportamento se deve à característica genética da VPA de apresentar maior quantidade de clorofila nas folhas do que o HS, pois as doses de $\mathrm{N}$ aplicadas no sistema de alto manejo foram maiores. Diferenças genéticas no TRC entre híbridos de milho foram reportadas por Argenta et al. (2004). Não houve efeito significativo da dose de $\mathrm{N}$ ou da inoculação 
Quadro 2. Rendimento de grãos, número de espigas por planta, número de grãos por espiga, número de grãos por $\mathrm{m}^{2}$, massa de 1.000 grãos de milho em razão do nível de manejo (alto e médio), da dose de nitrogênio e da inoculação ou não das sementes com Azospirillum, em Lages, SC, durante os anos agrícolas de 2011/2012 e 2012/2013

\begin{tabular}{|c|c|c|c|c|c|c|}
\hline Dose de N & Azospirillum & Rendimento de grãos & Espiga por planta & Grãos por espiga & Grãos por $\mathbf{m}^{2}$ & Massa de 1.000 grãos \\
\hline \multirow[t]{2}{*}{$\mathrm{kg} \mathrm{ha}^{-1}$} & & $\mathrm{~kg} \mathrm{ha-1}$ & \multicolumn{3}{|c|}{$\mathrm{n}^{\mathrm{o}}$} & \multirow[t]{2}{*}{$\mathrm{g}$} \\
\hline & & & & Nível alto & & \\
\hline \multirow[t]{2}{*}{0} & Sem & 8.344 & 1,03 & 440 & 2.848 & 293 \\
\hline & Com & 9.063 & 0,98 & 442 & 2.933 & 309 \\
\hline \multirow[t]{2}{*}{140} & Sem & 13.191 & 1,06 & 610 & 4.016 & 329 \\
\hline & Com & 13.335 & 1,02 & 402 & 3.966 & 335 \\
\hline \multirow[t]{2}{*}{280} & Sem & 16.444 & 1,01 & 656 & 4.577 & 359 \\
\hline & Com & 15.873 & 1,04 & 627 & 4.281 & 371 \\
\hline \multirow[t]{2}{*}{420} & Sem & 16.947 & 1,07 & 664 & 4.438 & 381 \\
\hline & Com & 16.917 & 1,00 & 624 & 4.315 & 392 \\
\hline \multirow[t]{2}{*}{ Média } & & $13.764 \mathrm{a}^{*}$ & $1,02 \mathrm{a}$ & $559 \mathrm{a}$ & $3.922 \mathrm{a}$ & $347 \mathrm{a}$ \\
\hline & & \multicolumn{5}{|c|}{ Nível médio } \\
\hline \multirow[t]{2}{*}{0} & Sem & 7.403 & 1,05 & 525 & 2.047 & 360 \\
\hline & Com & 5.986 & 0,99 & 441 & 1.623 & 366 \\
\hline \multirow[t]{2}{*}{65} & Sem & 8.908 & 1,04 & 605 & 2.380 & 373 \\
\hline & Com & 9.429 & 1,02 & 605 & 2.446 & 385 \\
\hline \multirow[t]{2}{*}{130} & Sem & 9.275 & 1,03 & 642 & 2.471 & 374 \\
\hline & Com & 9.684 & 1,02 & 621 & 2.447 & 397 \\
\hline \multirow[t]{2}{*}{195} & Sem & 9.306 & 0,94 & 510 & 2.221 & 420 \\
\hline & Com & 9.609 & 0,93 & 548 & 2.392 & 403 \\
\hline Média & & $8.700 \mathrm{~b}$ & $1,00 \mathrm{a}$ & $562 \mathrm{a}$ & $2.253 \mathrm{~b}$ & $385 \mathrm{~b}$ \\
\hline \multirow{2}{*}{$\begin{array}{l}\text { Média da } \\
\text { inoculação }\end{array}$} & Sem & $11.222 \mathrm{a}$ & $1,00 \mathrm{a}$ & $582 \mathrm{a}$ & $3.125 \mathrm{a}$ & $362 \mathrm{~b}$ \\
\hline & Com & $11.237 \mathrm{a}$ & $0,99 \mathrm{a}$ & $562 \mathrm{a}$ & $3.051 \mathrm{a}$ & $370 \mathrm{a}$ \\
\hline CV (\%) & & 8,34 & 5,73 & 9,40 & 8,96 & 4,38 \\
\hline
\end{tabular}

Médias seguidas por mesma letra minúscula na coluna não diferem significativamente pelo teste de Tukey a $5 \%$.

sobre o teor relativo de clorofila. Portugal et al. (2012) também não observaram influência da inoculação com Azospirillum sp. via foliar e da adubação nitrogenada em cobertura sobre o índice de clorofila foliar. Isso pode ser explicado porque quando a planta absorve quantidade excessiva de $\mathrm{N}$ o nutriente se acumula na forma de nitrato (Rambo et al., 2007). Dessa maneira, o N não se associa à molécula de clorofila, não sendo detectado pelo medidor de clorofila.

O rendimento de grãos foi influenciado significativamente pelo nível de manejo. Os maiores rendimentos foram alcançados no nível de alto manejo, independentemente da dose de $\mathrm{N}$ aplicada em cobertura ou da inoculação (Quadro 2). Os componentes do rendimento que contribuíram para que o nível de alto manejo alcançasse maiores rendimentos foram o número de grãos produzidos por área e a massa de 1.000 grãos. As maiores produtividades registradas no sistema de alto manejo decorreram do maior potencial produtivo do HS, em relação à VPA, da maior quantidade de fertilizantes aplicada na semeadura e em cobertura e da maior população de plantas adotada nesse sistema de cultivo. Não houve diferenças significativas no rendimento de grãos das parcelas inoculadas e não inoculadas. As parcelas inoculadas produziram grãos com maior massa do que as não inoculadas, na média das doses de $\mathrm{N}$ e dos níveis de manejo.

Nos dois níveis de manejo, o rendimento de grãos foi influenciado pelas doses de $\mathrm{N}$ em cobertura. No nível de manejo alto, o rendimento de grãos aumentou quadraticamente com os incrementos na dose de $\mathrm{N}$ tanto nas parcelas inoculadas quanto nas não inoculadas (Figura 3). Os maiores valores de rendimentos de grãos observados nesse nível de manejo foram obtidos com a aplicação de $420 \mathrm{~kg} \mathrm{ha}^{-1}$ de $\mathrm{N}$, que viabilizou rendimentos de $16.904 \mathrm{~kg} \mathrm{ha}^{-1}$ nas parcelas inoculadas e $17.004 \mathrm{~kg} \mathrm{ha}^{-1}$ nas não inoculadas. Os pontos de máxima obtidos a partir da primeira derivada das funções quadráticas ajustadas aos dados foram obtidos com a aplicação de $440 \mathrm{~kg} \mathrm{ha}^{-1}$ de N nas parcelas inoculadas e $449 \mathrm{~kg} \mathrm{ha}^{-1}$ naquelas onde não se fez a inoculação. 
(a)

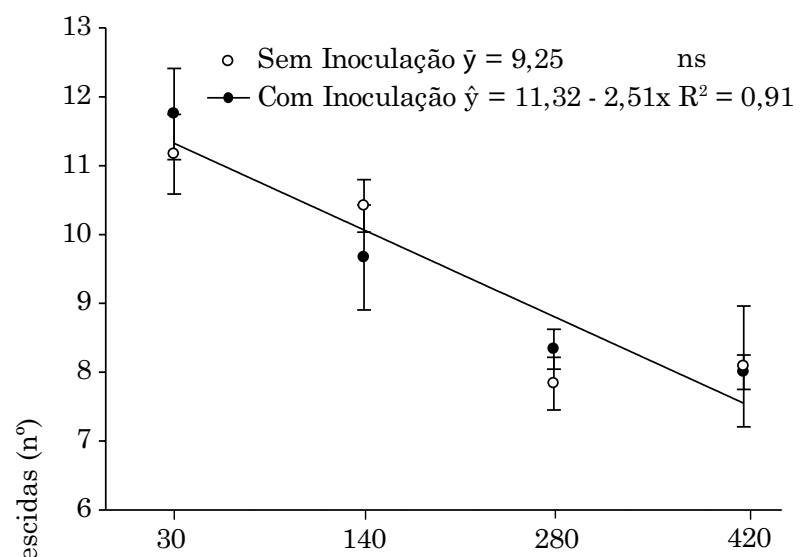

(b)

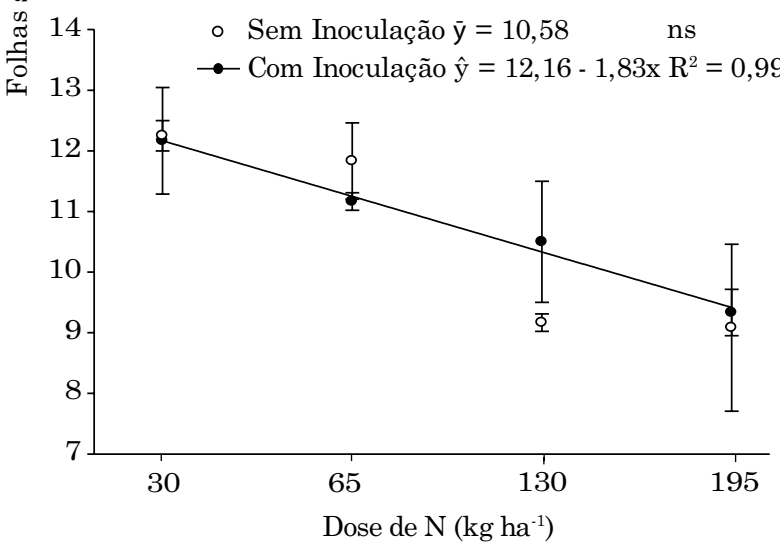

Figura 2. Número de folhas senescidas no espigamento do milho em função de doses de nitrogênio, com e sem inoculação das sementes com Azospirillum, nos níveis de manejo alto (a) e médio (b), em Lages, SC, durante os anos agrícolas de 2011/2012 e 2012/2013.

No nível de manejo médio, o rendimento de grãos também aumentou quadraticamente com o incremento na dose de $\mathrm{N}$ nas parcelas inoculadas; entretanto, não foi influenciado pela aplicação de $\mathrm{N}$ em cobertura nas não inoculadas (Figura 3). $\mathrm{O}$ ponto de máxima da função quadrática nas parcelas inoculadas foi alcançado com a aplicação de $144 \mathrm{~kg} \mathrm{ha}^{-1}$ de N. As respostas do rendimento de grãos à aplicação de $\mathrm{N}$ em cobertura foram menores no nível de manejo médio em razão das menores produtividades registradas nesse sistema de cultivo.

A eficiência agronômica de uso do N (EA) foi influenciada pela dose de $\mathrm{N}$ nos dois níveis de manejo. No sistema de alto manejo, a eficiência agronômica de uso do $\mathrm{N}$ diminuiu quadraticamente com o incremento na dose de $\mathrm{N}$, tanto nas parcelas inoculadas quanto nas não inoculadas (Figura 4). No nível de manejo médio, a eficiência de uso do $\mathrm{N}$ decresceu linearmente com o aumento da dose de $\mathrm{N}$ (a)
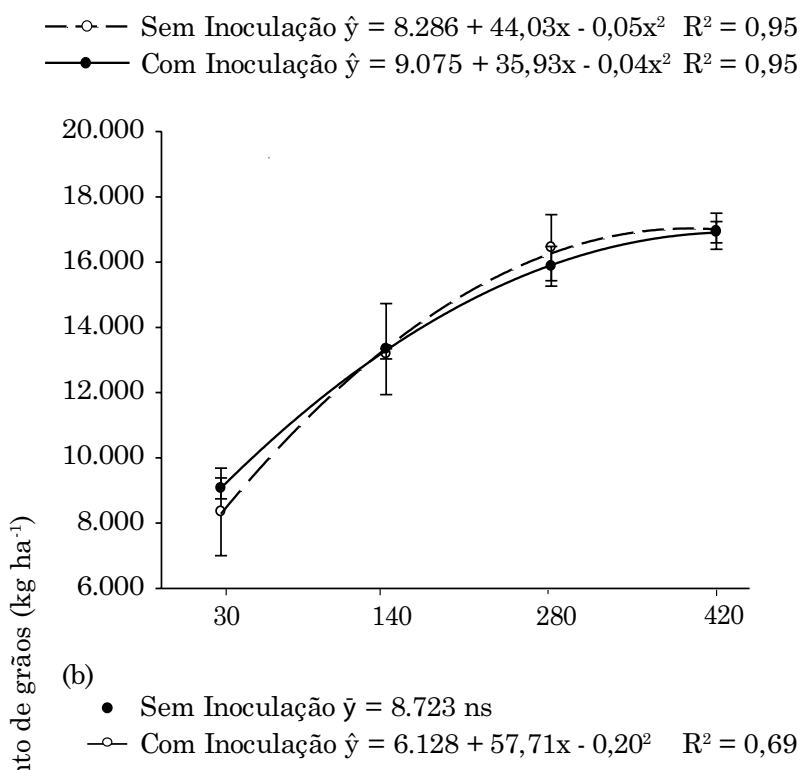$$
\text { 西 }
$$



Figura 3. Rendimento de grãos do milho em função de doses de nitrogênio, com e sem inoculação das sementes com Azospirillum, nos níveis de manejo alto (a) e médio (b), em Lages, SC, durante os anos agrícolas de 2011/2012 e 2012/2013.

nas parcelas inoculadas e de forma quadrática nas não inoculadas. Assim, observou-se que tanto nos tratamentos com inoculação quanto naqueles sem inoculação houve decréscimo na EA em razão do aumento das doses de N, sendo os tratamentos mais eficientes no uso do $\mathrm{N}$ quando não houve aplicação de $\mathrm{N}$ em cobertura; apenas foi utilizada a dose de $30 \mathrm{~kg} \mathrm{ha}^{-1}$ na semeadura. Mota (2013), testando eficiência de fontes de adubação nitrogenada com polímeros para liberação lenta de nitrogênio, também verificou redução na EUN com o aumento da dose aplicada, em sintonia com a lei dos rendimentos decrescentes. Não houve diferenças significativas entre os dois níveis de manejo, nem entre as parcelas inoculadas e não inoculadas, quanto à EUN. 
(a)

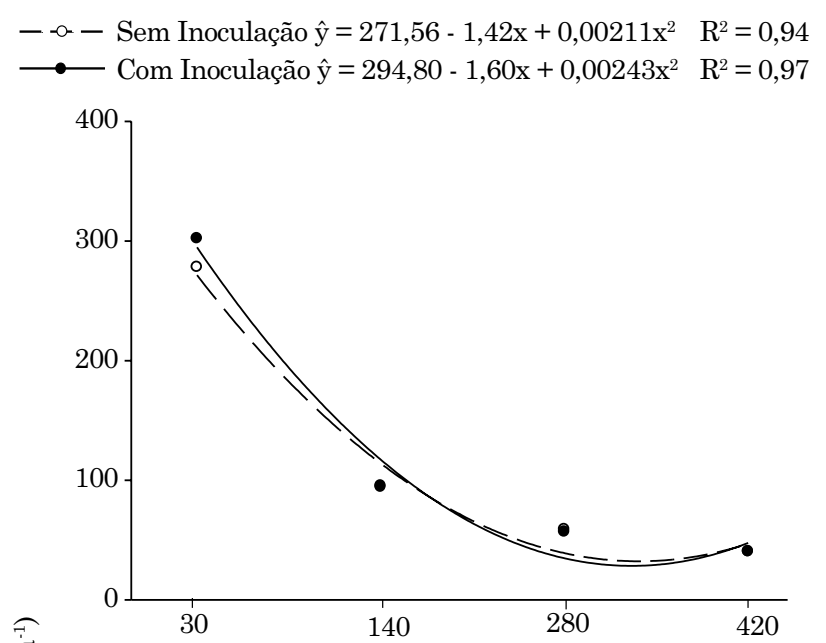

(b)

- - - - Sem Inoculação $\hat{y}=246,66-2,01 x+0,0051 x^{2} R^{2}=1,00$

$\longrightarrow$ Com Inoculação $\hat{y}=195,29-0,8021 x \quad R^{2}=0,97$

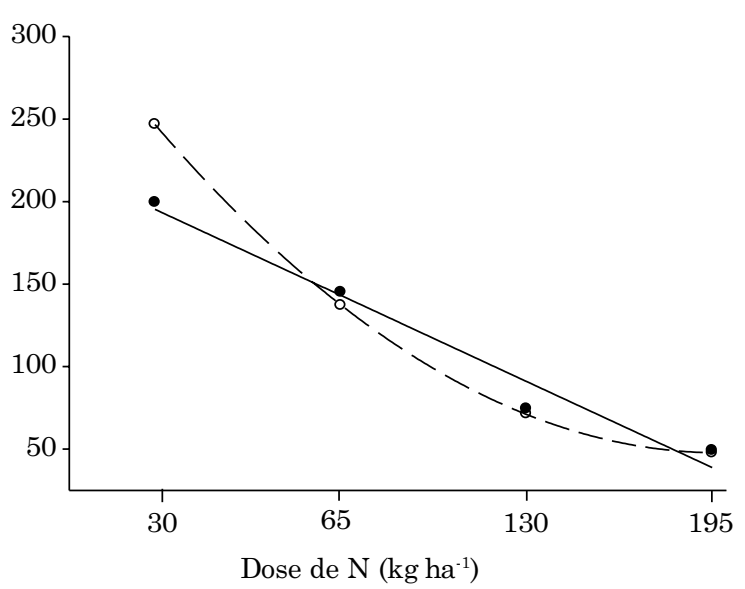

Figura 4. Eficiência agronômica de uso do nitrogênio (EUN) do milho em função de doses de nitrogênio, com e sem inoculação das sementes com Azospirillum, nos níveis de manejo alto (a) (parte superior) e médio (b) (parte inferior), em Lages, SC, durante os anos agrícolas de 2011/2012 e 2012/2013.

Este trabalho foi conduzido com base em duas hipóteses: a primeira, utilizar Azospirillum é estratégia para suprir parte da demanda nitrogenada do milho, reduzindo a quantidade de fertilizante mineral aplicada na cultura para produtores com baixa capacidade de investimento em fertilizantes nitrogenados; e a segunda, as bactérias diazotróficas podem aumentar a eficiência de uso do nitrogênio e contribuir para elevar o potencial produtivo do milho, em associação ao fertilizante nitrogenado mineral, para produtores com alta capacidade de investimento em manejo. Os resultados obtidos não confirmaram essas hipóteses (Figuras $3 \mathrm{e}$ 4), pois não houve diferenças significativas entre parcelas inoculadas e não inoculadas quando não se utilizou $\mathrm{N}$ ou quando se empregou metade da dose recomendada no sistema de médio manejo, nem tão pouco se constatou efeito benéfico da inoculação quando se empregou a dose recomendada ou 1,5 vez o valor necessário para obter $18.000 \mathrm{~kg} \mathrm{ha}^{-1}$ no sistema de alto manejo.

Os resultados reportados na literatura sobre os efeitos do Azospirillum sp. no desempenho agronômico do milho são bastante variados. Roesch et al. (2006) verificaram que a colonização de plantas de milho por bactérias diazotróficas foi inibida por altas doses de $\mathrm{N}$ durante os primeiros estádios de crescimento. Isso ocorreu porque o $\mathrm{N}$ mineral alterou o estado fisiológico da planta e, por consequência, a sua associação às bactérias diazotróficas. $\mathrm{O}$ alto teor de matéria orgânica do solo em que se conduziu o trabalho $\left(50,0 \mathrm{~g} \mathrm{~kg}^{-1}\right)$ pode ter aumentado a disponibilidade de $\mathrm{N}$ às plantas, mitigando os benefícios da inoculação das sementes com Azospirillum sp. Campos et al. (2000), Godoy et al. (2011), Repke et al. (2013) e Vogt et al. (2014), avaliando inoculantes à base de Azospirillum spp. na cultura do milho em condições de campo, também não encontraram benefícios consistentes da utilização das bactérias diazotróficas sobre a produtividade. No entanto, Cavallet et al. (2000) e Hungria (2010) obtiveram ganhos de produtividade na ordem de 17 e $9 \%$, respectivamente, com o uso da bactéria Azospirillum spp. em milho.

Os efeitos da adubação nitrogenada e da inoculação com Azospirillum sp. na nutrição e produtividade do milho dependem da cultivar utilizada e das condições edafoclimáticas vigentes (Duarte et al., 2012). Influências geográficas e ambientais podem gerar associações diferentes entre bactérias diazotróficas endofíticas e plantas de milho, ocasionando resultados bastante variáveis em relação à inoculação (Roesch et al., 2006).

Os fatores que interferem nas respostas das culturas à inoculação com Azospirillum ainda não estão totalmente esclarecidos. Os resultados de sucesso encontrados na literatura da associação milho-Azospirillum estão relacionados, na maioria das situações, a fatores da própria bactéria, como a escolha da estirpe, o número ideal de células por semente e a sua viabilidade, bem como a compatibilidade entre estirpe e genótipo utilizado (Mehnaz e Lazarovits, 2006).

Não se constataram neste trabalho benefícios consistentes da inoculação das sementes com estirpes de Azospirillum brasiliense no rendimento de grãos e na eficiência de uso do $\mathrm{N}$ do milho, indicando que essa tecnologia não está consolidada como estratégia de manejo para melhorar o desempenho agronômico da cultura no Brasil. 


\section{CONCLUSÕES}

O rendimento de grãos do milho aumentou com o incremento nas doses de nitrogênio mineral em sistemas de alto manejo, independentemente da inoculação das sementes com Azospirillum.

O tratamento de sementes com Azospirillum não contribuiu para aumentar o rendimento de grãos do milho, independentemente do sistema de manejo e da dose de nitrogênio mineral.

\section{AGRADECIMENTOS}

Ao CNPq, pela concessão da bolsa de produtividade em pesquisa ao primeiro autor; à CAPES, pela concessão de bolsas de estudo ao segundo e terceiro autores; e a FAPESC, pela concessão de bolsa de estudo ao quarto autor deste trabalho.

\section{REFERÊNCIAS}

Argenta G, Silva PRF, Sangoi L. Leaf Relative chlorophyll content as an indicator parameter to predict nitrogen fertilization in maize. Ci Rural. 2004;34:1379-87.

Baldani JI, Baldani VLD. History on the biological nitrogen fixation research in graminaceous plants: special emphasis on the Brazilian experience. An Acad Bras Ci. 2005;77:549-79.

Bartchechen A, Fiori CCL, Watanabe SH, Guarido RC. Efeito da inoculação de Azospirillum brasiliense na produtividade da cultura do milho (Zea mays L.). Campo Digital. 2010;5:56-9.

Campos BH C, Theisen S, Gnatta V. Avaliação de inoculante Graminante na cultura do milho. Ci Rural. 2000;30:713-5.

Cassán FD, Garcia de Salamone I. Azospirillum sp.: cell physiology, plant interactions and agronomic research in Argentina. Buenos Aires: Asociación Argentina de Microbiologia; 2008.

Cavallet LE, Pessoa ACS, Helmich JJ, Helmich PR, Ost CF. Produtividade do milho em resposta à aplicação de nitrogênio e inoculação das sementes com Azospirillum spp. R Bras Eng Agric Amb. 2000;4:129-32.

Coelho AM, França GE, Pitta GVE, Alves VMC, Hernani LC. Cultivo de milho. Sete Lagoas: Embrapa; 2000. [Acessado 8 jun. 2012]. Disponível em: http://sistemasdeproducao.cnptia.embrapa. br/FontesHTML/Milho/CultivodoMilho/feraduba.htm.

Comissão de Química e Fertilidade do Solo - CQFSRS/SC. Manual de adubação e calagem para os estados do Rio Grande do Sul e Santa Catarina. 10 .ed. Porto Alegre: Sociedade Brasileira de Ciência do Solo; 2004.

Companhia Nacional De Abastecimento - Conab. Central de Informações Agropecuárias. [Acessado 28 set. 2013] Disponível em: http://www.conab.gov.br/OlalaCMS//13_09_boletim_ portugues_setembro_2013.pdf.

Correa OS, Romero AM, Soria MA, De Estrada M. Azospirillum brasilense-plant genotype interactions modify tomato response to bacterial diseases, and root and foliar microbial communities. In: Cassán FD, Garcia de Salamone I, editors. Azospirillum sp. cell physiology, plant interactions and agronomic research in Argentina. Buenos Aires: Asociación Argentina de Microbiologia; 2008. p.87-95.

Debruin J, Butzen S. Nitrogen uptake in corn. Johnston, IA [USA]: DuPont Pioneer; 2014. (Crop Insights, 24/4). Disponível em: https:// www.pioneer.com/home/site/us/agronomy/library/n-uptake-corn/.

Dobbelaere S, Vanderleyden J, Okon Y. Plant growth-promoting effects of diazotrophs in the rhizosphere. Crit Rev Plant Sci. 2003;22:107-49.

Duarte AP, Piedade RC, Martins VC, Cantarella H, Barros VLNP. Resposta de cultivares de milho ao nitrogênio em cobertura e à inoculação com Azospirillum. In: Anais do $29^{\circ}$ Congresso Nacional de Milho e Sorgo; 2012; Águas de Lindóia. Campinas: Instituto Agronômico; 2012. p.1786-92.

Empresa Brasileira de Pesquisa Agropecuária - Embrapa. Centro Nacional de Pesquisa de Solos. Sistema brasileiro de classificação de solos. $2^{\text {a }}$.ed. Brasília: 2006.

Fageria NK, Baligar VC. Enhancing nitrogen use efficiency in crop plants. Adv Agron. 2005;88:97-185.

Godoy JCS, Watanabe SH, Fiori CCL, Guarido RC. Produtividade de milho em resposta a doses de nitrogênio com e sem inoculação das sementes com Azospirillum brasilense. Campo Digital. 2011;6:26-30

Hungria M, Campo RJ, Souza EMS, Pedrosa FO. Inoculation with selected strains of Azospirillum brasilense and A. lipoferum improves yields of maize and wheat in Brazil. Plant Soil. 2010;331:413-25.

Lambrecht M, Okon Y, Van de Broek A, Vanderleyden, J. Indole-3-acetic acid, a reciprocal signalling molecule in bacteria-plant interaction. Trends Microbiol. 2000;8:298-300.

Lara Cabezas WAR, Trivelin PCO, Kornodôrf GH, Pereira S. Balanço da adubação nitrogenada sólida e fluida de cobertura na cultura do milho em sistema plantio direto no Triângulo Mineiro. R Bras Ci Solo. 2000;14:363-76.

Mehnaz S, Lazarovits G. Inoculation effects of Azospirillum lipoferum on corn plants growth under greenhouse conditions. Microbiol Ecol. 2006;51:326-35.

Mota MR. Fontes de liberação lenta como alternativa para aumentar a eficiência de uso do nitrogênio e o rendimento de grãos do milho [dissertação]. Lages, SC: Universidade do Estado de Santa Catarina; 2013.

Portugal JR, Arf, O, Longui WV, Gitti DC, Barbieri MKF, Gonzaga AR, Teixeira DS. Inoculação com Azospirillum brasilense via foliar associada a doses de nitrogênio em cobertura na cultura do milho. In: Anais do $29^{\circ}$ Congresso Nacional de Milho e Sorgo; 2012; Águas de Lindóia. Campinas: Instituto Agronômico, 2012. p.1413-7.

Prakamhang J, Minamisawa K, Teamtaisong K, Boonkerd N, Teaumroong N. The communities of endophytic diazotrophic bacteria in cultivated Rice (Oryza sativa L.). Appl Soil Ecol. $2009 ; 42 ; 141-9$.

Quadros PD. Inoculação de Azospirillum spp. em sementes de genótipos de milho cultivados no Rio Grande do Sul [dissertação]. Porto Alegre: Universidade Federal do Rio Grande do Sul; 2009.

Rambo L, Silva PRF, Strieder ML, Sangoi L, Bayer C, Argenta G. Monitoramento do nitrogênio na planta e no solo para predição da adubação nitrogenada em milho. Pesq Agropec Bras. 2007;42:407-17. 
Reis VM, Baldani VLD, Baldani JI, Döbereiner J. Biological nitrogen fixation in gramineae and palm trees. Crit Rev Plant Sci. 2000;19:227-47.

Reis VM, Teixeira KRS. Fixação biológica do nitrogênio - Estado da arte. In: Aquino AM, Assis RL, editores. Processos biológicos no sistema solo-planta: ferramentas para uma agricultura sustentável. Brasília: Embrapa Informação Tecnológica; 2005. p.350-68.

Repke RA, Cruz SJS, Silva CJ, Figueiredo PG, Bicudo SJ. Eficiência do Azospirillum brasiliense combinada com doses de nitrogênio no desenvolvimento de plantas de milho. R Bras Milho Sorgo. 2013;12:214-26.

Ritchie SW, Hanway JJ, Benson GO. How a corn plant develops. Ames: Iowa State University of Science and Technology; 1993. (Special Report, 48).

Rodrigues LS, Baldani VLD, Reis VM, Baldani JI. Diversidade de bactérias diazotróficas endofitícas dos gêneros Herbaspirillum e Burkholderia na cultura do arroz inundado. Pesq Agropec Bras. 2006;41:275-84.
Roesch LFW, Olivares FL, Passaglia LPM, Selbach PA, Sá ELS, Camargo FAO. Characterization of diazotrophic bacteria associated with maize: effect of plant genotype, ontogeny and nitrogen-supply. World J Microbiol Biotechnol. 2006;22:967-74.

Sangoi L, Silva PRF, Argenta G, Rambo L. Ecofisiologia da cultura do milho para altos rendimentos. Lages: Graphel; 2010a.

Sangoi L, Silva PRF, Argenta G. Estratégias de manejo do arranjo de plantas para aumentar o rendimento de grãos do milho. Lages: Graphel; 2010b.

Silva ED, Buzetti S, Lazarini E. Aspectos econômicos da adubação nitrogenada na cultura do milho em sistema de plantio direto. $\mathrm{R}$ Bras Milho Sorgo. 2005;4:286-97.

Vogt GA, Balbinot Junior AA, Galotti GJM, Padolfo CM, Zoldan $\mathrm{S}$. Desempenho de genótipos de milho na presença ou ausência de inoculação com Azospirillum brasiliense e adubação nitrogenada de cobertura. Agropec Catarinense. 2014;27: 49-54. 